\title{
ERRATUM
}

\section{To the articles}

"Reasons for the Formation of Cords in Melting Electovacuum Strontium glass in a Flame Tank Glassmelter of New Design" by L. Kemeklis, A. Balandis, and G. Vaitskyalenis [Glass and Ceramics, Volume 61, Numbers 7 - 8, pages 248 - 251 (2004)]

"Change in Transmission Coefficient of Screen Glass Melting in a Flame Tank Furnace" by A. Balandis and G. Vaitskyalionis [Glass and Ceramics, Volume 61, Numbers 11 - 12, pages 399 - 401 (2004)]

"Upgrade of Preparation of Batch Mixed with Cullet in Melting electrovacuum Glass" by A. Tumas, L. Kemeklis, A. Balandis, and G. Vaistkyalionis [Glass and Ceramics, Volume 63, Numbers 1 - 2, pages 14 - 16 (2006)]

In the above articles, the last author's name should read G. Vaickelionis.

The Publisher apologizes to the author for this error. 